\section{EDITB : A program to aid processing of event records}

\author{
B. S. CARTER \\ Department of Growth and Development, \\ Institute of Child Health, \\ London, England WCl $\mathrm{N} 1 \mathrm{EH}$
}

A shorthand code has been devised by BlurtonJones (Note 1) as a successor to that of Leach (1972). The purpose of the code is to aid the recording of a running commentary on children, their parents and other people interacting as a group. The records consist of a sequence of two-character codes representing people, things, actions, and so on, with the possibility for insertion of text in noncoded form. The coded text is interposed with time markers separating the passage of each $15 \mathrm{sec}$ of real time. EDITB takes the coded text as input, checks the syntax of this text, and counts the occurrence of each individual code within the text of the observation. The program counts and records the times of occurrence of particular sentences within the text. A count of user-specified sequences may also be made. There is a set of computer programs written to analyze texts, written in the code of Leach, known as PRIMATE (Humphries, 1972), so in a sense EDITB may be regarded as a successor to PRIMATE, although the aims of EDITB are more limited in scope. EDITB will, as an option, take as input texts written to be analyzed with PRIMATE.

Input. The input to EDITB is in two parts, both in card image form. One part consists of a list of possible codes to be encountered within the text of the observations to be analyzed. Two-letter codes denote subjects, verbs, or objects. Codes starting with a comma, an asterisk, or a left bracket represent distance markers or plain language delimiters, time markers, and observation brackets, respectively. Finally, the first input stream contains a list of commands for the program, for example, to change default settings for permissible codes for a part of sentences, to provide expanded forms for any or all of the codes, or to specify which sentences are to be timed or counted. The two-letter codes may be expanded up to 10-character widths. The expanded forms of the codes are not necessary for the program itself but may make the output more legible. Other commands allow for checking the syntax of the observation, accumulation of counts over more than one ob-

This code was first used in a study called "Dimensions of attachment," financed by the United Kingdom Social Science Research Council, Project Grant HR 1745. A description of the recording code may be obtained from N. Blurton-Jones at the same address as the author for the cost of copying (three pages). The fuller documentation of EDITB also contains a description of the grammar and syntax of the recording code. servation, the provision of PRIMATE-style input, or the specification of the maximum line length to be considered.

The second part of the input to EDITB contains the observations. Each observation is preceded by a line containing identifying information in numeric form. The observation is signaled by ( $R$ at the start of a line. This is followed by the text proper. Notationally, each action is described by a sentence having a subject, a verb, and an object. However, if the subject remains the same during a sequence of events, there is no need to record it more than once. Similarly, if the object remains the same, this too is coded only once. Time markers are not considered to be part of any particular sentence, but distance and plain language sections are counted as verbs. A blank space or the edge of the defined card marks the end of each line observation. Thus, the length of each particular data line is under the control of the transcriber. The end of a particular observation is signaled by a ( $\mathrm{S}$ code. A new observation, together with its identifying line(s), may be input immediately afterward and analyzed in the same run.

Output. Like the input, the output is in two parts. However, unlike the input, one of the parts is contained within the other. A complete listing of the dictionary is the first thing to be put onto the output. Then a sequential listing of the commands: each command followed by its qualifying information. In the printout for the timing and counting of sentences, and for the sequence analysis, each sentence is printed with the short and the expanded forms of its components.

The print of the dictionary is followed by the identiying information for the first observation and then the text of the observation itself. When EDITB finds some incorrect data, illegal syntax, or unrecognized code, the position is noted in the line and the line is followed by a list of the errors found within that line.

The observation text is followed by a list of all codes that occur within the text and the number of times each of these codes occurs within the text.

Code commands are followed by a listing of timed sentences. This line contains the complete sentence, its time from the beginning of the observation in minutes and seconds, and the number of the sentence. The first sentence in the observation is designated Number 1, the second sentence Number 2, and so on. The plain language comments together with the time at each comment, are put in order among the timed sentences.

Timed sentences are followed by the sentence counts for the observation. These counts may be of particular sentences or all sentences with a particular subject, verb, or object, or any particular category of subject, verb, or object. These are followed by the sequence counts.

The smaller output contains the identification lines 
Figure 1. The main output file from EDITB using a brief section of an observation and using many of the available options.

\begin{tabular}{|c|c|c|c|c|c|c|c|c|c|c|c|c|c|c|}
\hline AK & AL & AN & AP & AR & AS & AT & AW & $\mathrm{AZ}$ & & & & & & DICTION \\
\hline BK & BL & BM & BP & BQ & BR & BT & BV & BW & $\mathrm{BZ}$ & & & & & DICTION \\
\hline DK & DL & DM & DN & DP & DQ & DR & DS & DV & DW & & & & & DICTION \\
\hline EK & EL & EN & EQ & ER & $\mathrm{ES}$ & ET & EW & & & & & & & DICTION \\
\hline IK & IL & IP & IQ & IR & IS & IV & IW & & & & & & & DICTION \\
\hline JK & $\mathrm{JL}$ & $\mathrm{JM}$ & JN & $\mathbf{J P}$ & JQ & $\mathrm{JR}$ & JS & JT & JV & JW & JX & $\mathrm{JZ}$ & & DICTION \\
\hline OK & OM & OP & OQ & OR & OS & OT & & & & & & & & DICTION \\
\hline UK & UL & UM & UN & UP & UQ & UR & US & UT & UV & UW & $\mathbf{U X}$ & $\mathrm{UZ}$ & & DICTHON \\
\hline YK & YL & IM & YN & YP & YQ & YR & YS & YT & YV & YW & YY & YX & $\mathbf{Y Z}$ & DICTI \\
\hline,$Z$ &, $\mathbf{U}$ & ,I & , 0 &, $\mathbf{J}$ &, $\mathbf{K}$ & ,L & ,M &,$£$ &, & ,P & ,G & & & DICTI \\
\hline (R & (S & & & & & & & & & & & & & DICTI \\
\hline${ }^{*} \mathrm{~K}$ & ${ }^{*} \mathrm{~L}$ & ${ }^{*} \mathrm{~W}$ & *X & & & & & & & & & & & DICTI \\
\hline
\end{tabular}

INITIAL LETTERS ARE $-\begin{array}{llllllllllll} & - & \text { A } & \text { B } & \text { E } & \text { I } & \text { J } & 0 & \text { U } & \text { Y } & \text {, } & \left(^{*}\right.\end{array}$

CODES FOR CATEGORIES ARE

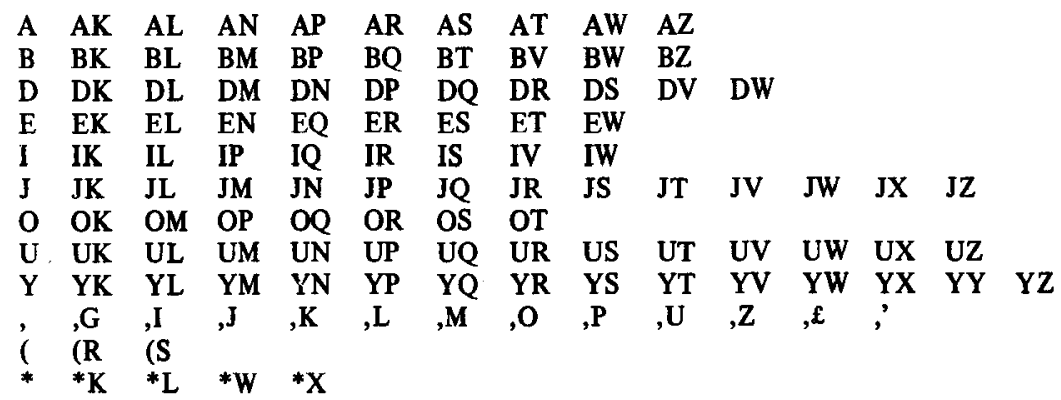

\section{EXPAND}

$\begin{array}{ll}\text { AP } & \text { PROFFER } \\ \text { AZ } & \text { PLACE } \\ \text { EL } & \text { LOOK } \\ \text { ES } & \text { SMILE } \\ \text { EW } & \text { WATCH } \\ \text { IP } & \text { APPROACH } \\ \text { IR } & \text { RETURN } \\ \text { IV } & \text { LEAVE } \\ \text { JR } & \text { DOOR/GATE } \\ \text { JS } & \text { OBJECT } \\ \text { JZ } & \text { BASE } \\ \text { OM } & \text { DEMONSTRAT } \\ \text { OP } & \text { MANIP } \\ \text { UT } & \text { TALK } \\ \text { YK } & \text { CHILD } \\ \text { YM } & \text { MOTHER } \\ \text { YS } & \text { SELF } \\ \text {,Z } & \text { CONTACT } \\ \text { U } & \text { 1FOOT } \\ \text {,I } & \text { 2FEET } \\ \text {,O } & \text { 3FEET }\end{array}$

DICT1 5

DICTION 21

DICTION 26

DICTION 51

DICTION 55

DICTION 57

DICTION 84

DICTION 86

DICTION 88

DICTION 96

DICTION 97

DICTION1 02

DICTION104

DICTION1 05

DICTION118

DICTION123

DICTION1 25

DICTION1 30

DICTION1 36

DICTION137

DICTION138

DICTION139

SYNTAX

LINELENGTH $\quad 72$

DICTION146

COUNTSENTENCE

YMUTYK MOTHER TALK CHILD

YKUTYM CHILD TALK MOTHER

DICTION147

DEMO 1

DEMO 2

DEMO 3

TIMESENTENCES

YMU YK MOTHER ALLU CHILD

YKELJR CHILD LOOK DOOR/GATE

DEMO 4

YKU YM CHILD ALLU MOTHER

DEMO 5

DEMO 6

DEMO 7

EXACTINTERVALS

SEQUENCE

YMUTYK MOTHER TALK CHILD YKUTYM CHILD TALK MOTHER

YMUTYK MOTHER TALK CHILD YKUTYM CHILD TALK MOTHER

YMUTYK MOTHER TALK CHILD YKUTYM CHILD TALK MOTHER

${ }^{*} \mathbf{K}$

DEMO 8

DEMO 9

YKOPJX CHILD MANIP JX YKELJR CHILD LOOK DOOR/GATE YMDSYS MOTHER DS. SELF DEMO 13 
87015056237209259999050401299999999000000000090

(RYMUTYKYKOPJX,IYMYMIVJZ,OYKAZ

YKYMIP,ZYK*KYMIV,OYKIRJZ

YKOPJX,IYM*KYKELYMUTYM

YMUTYKYKELUTAPYMYMUTYK

YKBPJXUTYMYMESUTYK*K

YMEWYKYKOPJX,UYMELJRYMDS

YS*L

YKOPJX,UYMYMDSYSYKOPJXAP

YMUTYMYMOMUTYK*K(S

$\begin{array}{rr}\text { 43679DATA } & 3 \\ \text { 43680DATA } & 4 \\ \text { 43681DATA } & 5 \\ \text { 43682DATA } & 6 \\ \text { 43683DATA } & 7 \\ \text { 43684DATA } & 8 \\ \text { 43748DATA } & 72 \\ \text { DEMO } & 14 \\ \text { 43759DATA } & 74 \\ \text { DEMO } & 15\end{array}$

PLACE 1

SMILE
RETURN
JX
MANIP
MOTHER
3FEET
(S

$\begin{array}{lll}1 & \text { WATCH } & 1 \\ 1 & \text { LEAVE } & 2\end{array}$

6 BASE 2

6 BASE 2

24 SELF 2

2 1FOOT

2
2 CONTACT 1

PLAIN LANGUAGE COMMENTS AND SENTENCE TIMES 87015056237209259999050401299999999000000000090

43679DATA

\begin{tabular}{lcccc} 
& MIN & SEC & \multicolumn{2}{c}{ SINCE LAST VERBS } \\
MOTHER TALK CHILD & 0 & 0 & & 1 \\
CHILD TALK MOTHER & 0 & 30 & 30 & 15 \\
MOTHER TALK CHILD & 0 & 30 & 0 & 16 \\
CHILD TALK MOTHER & 0 & 30 & 0 & 19 \\
MOTHER TALK CHILD & 0 & 30 & 0 & 20 \\
CHILD TALK MOTHER & 0 & 30 & 0 & 22 \\
MOTHER TALK CHILD & 0 & 30 & 0 & 24 \\
CHILD LOOK DOOR/GATE & 0 & 45 & 15 & 28 \\
CHILD TALK MOTHER & 1 & 0 & 15 & 35 \\
MOTHER TALK CHILD & 1 & 0 & 0 & 37
\end{tabular}

SENTENCE COUNTS

$\begin{array}{lcr}\text { MOTHER } & \text { TALK } & \text { CHILD } \\ \text { CHILD } & \text { TALK } & \text { MOTHER }\end{array}$

COUNT THIS OBSERVATION IS

COUNT THIS OBSERVATION IS
5

4

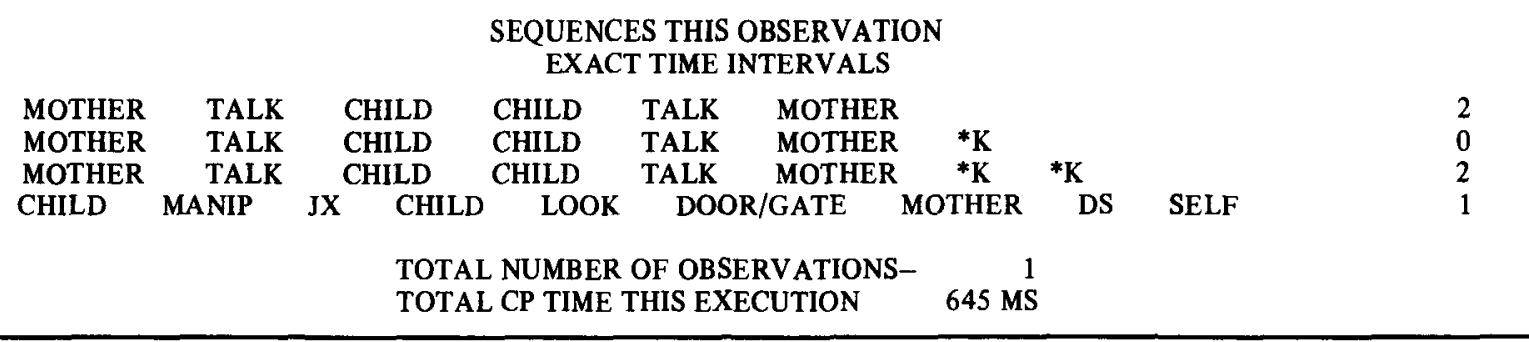

for the observation and the sentence timings only. Thus further analysis may be performed on this summarized data set.

Language and Computers. EDITB is written in PASCAL. The original version is written for the CDC implementation available at the University of London Computer Center. The current version is independent of the particular implementation as far as possible. The program is now portable to any PASCAL implementa- tions that allows 48-element sets and operates on strings of eight or more characters. EDITB is designed to be compatible with a large number of character sets.

Usage. EDITB has been used to follow and count the occurrences of particular behaviors in several studies originated at the Institute of Child Health. Each observation is held as a connected sequence of sentences. This structure is to allow expansion of the program to follow sequences of sentences, or groups of sentences within a 
given time span. When used with a 30 -line observation the storage used is less than 40,000 octal words. Such an observation takes about $2 \mathrm{sec}$ to analyze on the 6600 . This time includes the printing of several timings, counts, and sequences. When EDITB is used simply as a check of the observations syntax, the time will be shortened considerably.

Availability. Listings on microfiche, either $24 \mathrm{X}$ or $42 \mathrm{X}$, are available from the author free of charge. Fuller documentation including a description of the code (50 A4 pages) is available for the cost of copying; this is currently $\$ 6$. Tape copies are available free of charge; however, recipients will be asked to pay postage and return the tape.

\section{REFERENCE NOTE}

1. Blurton-Jones, N. Dimensions of attachment. In preparation.

\section{REFERENCES}

Humphries, P. PRIMATE. In N. Blurton-Jones (Ed.), Ethological studies in child development. Cambridge, England: Cambridge University Press, 1972. Pp. 278-281.

LEACH, G. M. A comparison of the social behavior of some normal and abnormal children. In N. Blurton-Jones (Ed.), Ethological studies in child development (Chapter 10). Cambridge, England: Cambridge University Press, 1972.

(Accepted for publication April 10, 1978.) 